\title{
CRISE DA MODERNIDADE, NIILISMO E SENTIDO: LIMA VAZ INTÉRPRETE DO SEU TEMPO (I)
}

\author{
The crisis of modernity, nihilism and meaning: Lima Vaz, an interpreter \\ of his time \\ Juliano de Almeida Oliveira *
}

Resumo: $\mathrm{O}$ presente artigo é o primeiro de dois estudos que procuram investigar a concepção que Lima Vaz tem da modernidade e de sua crise, do emergir do niilismo no mundo contemporâneo, bem como da busca de sentido que ainda se é instado a realizar pela própria condição humana, malgrado as desconfianças que o contexto atual lança a essa atividade filosófica. Esta primeira parte trata da caracterização da modernidade e de sua interpretação por Lima Vaz, como evento do refluxo do fundamento do sentido para o sujeito humano enquanto pensante. Também será iniciada a abordagem do fenômeno da crise do projeto moderno.

Palavras-chave: Modernidade. Sujeito. Razão. Crise. Lima Vaz.

Abstract: This article is the first of two studies aiming to investigate Lima Vaz's conception of modernity and of its crisis, the emergence of the nihilism in contemporary age, and also the search for meaning inherent to the human condition, still alive, despite the current mistrust regarding this philosophical activity. This first part aims to characterize modernity and how it is interpreted by Lima Vaz, as an event transfering the foundation of meaning to the thinking subject. Furthermore, it will also start approaching the issue of the crisis of modernity. Keywords: Modernity. Human Subject. Reason. Crisis. Lima Vaz.

* Doutor em Filosofia. Professor da Faculdade Católica de Pouso Alegre e da Universidade do Vale do Sapucaí. Artigo recebido em 15/01/2019 e aprovado para publicação em01/05/2019. 


\section{Introdução}

$\mathrm{O}$ pensamento filosófico se dá em contextos histórico-teóricos bem definidos. Ninguém pode, com efeito, filosofar sem se referir ao modus vivendi et cogitandi de sua própria época, já que cada pensador traz consigo as marcas e inquietudes, as possibilidades e limites de seu tempo. De outro lado, igualmente, não se podem desprezar as lições do passado. Assim, quando o estudioso da filosofia busca conhecer de modo aprofundado o que autores a ele anteriores lograram alcançar em sua aventura intelectual, procura aprender deles o modo de aproximar-se ao sentido do real para poder enfrentar com mais perspicácia e acuidade as questões do presente.

Trata-se do dinamismo que move a história da filosofia no repensar as obras significativas do passado com atenção às questões atuais, que Lima Vaz ${ }^{1}$, na esteira da herança hegeliana, denomina de rememoração (Erinnerung), entendida por ele como primeiro passo do método de trabalho filosófico ${ }^{2}$. Ela indica que a reflexão sobre os temas fundamentais da existência não começa hic et nunc, mas tem uma história que sempre precisa ser levada em consideração. Como afirma Mac Dowell,

(...) o progresso da Filosofia apresenta-se como uma permanente reinvenção, onde se conjugam continuidade e descontinuidade, não repetição mecânica do já dito, mas iniciativa de sua inteira reproposição sob a forma de espontânea criação. Manifestação, por um lado, da invariância fundamental da natureza humana, na constância da problemática, sempre recorrente em níveis diversos, a rememoração remete, por outro, à radical historicidade do pensar, aberto permanentemente a novos horizontes interpretativos ${ }^{3}$.

\footnotetext{
${ }^{1}$ Para este estudo, servem como referências fundamentais os seguintes textos de Henrique Cláudio de Lima Vaz: (a) Livros: Antropologia Filosófica I. São Paulo: Loyola, 1991 (AF I); Escritos de Filosofia II: Ética e cultura. São Paulo: Loyola, 1988 (EF II); Escritos de Filosofia III: Filosofia e cultura. São Paulo: Loyola, 1997 (EF III); Escritos de Filosofia VII: Raízes da modernidade. São Paulo: Loyola, 2002 (EF VII); (b) Artigos: Além da modernidade. Sintese Nova Fase, 53, 1991, p. 241-254 (AM); “Entrevista". In: NOBRE, M.; REGO, J. M. Conversas com filósofos brasileiros. São Paulo: Ed. 34, 2000, p. 29-44 (CFB); Ética e civilização. Síntese Nova Fase, n. 49, 1990, p. 5-14 (ECI); Ética e comunidade. Sintese Nova Fase, n. 52, 1991, p. 5-11 (ECO); Ética e razão moderna. Síntese Nova Fase, n. 68, 1995, p. 53-85 (ERM); Humanismo hoje: tradição e missão. Síntese, n. 91, 2001, p. 157-168 (HH); Morte e vida da Filosofia. Síntese Nova Fase, n. 55, 1991, p. 677-691 (MVF); Religião e modernidade filosófica. Síntese Nova Fase, n. 53, 1991, p. 147-165 (RMF); Sentido e não-sentido na crise da modernidade. Síntese Nova Fase, n. 64, 1994, p. 5-14 (SNS).

2 "Para mim, o exercício do ato de filosofar é sempre uma 'rememoração' (uma Erinnerung, como diria Hegel) e uma 'atenção' que podemos chamar conceptualizante, ou seja, pensada, refletida e discursivamente explicada, à realidade (...). Filosofia é anámnesis - recordação - e é nóesis - pensamento". MVF, p. 684-685.

${ }^{3}$ MAC DOWELL, J. A. Método dialético, história e transcendência no sistema filosófico de Henrique de Lima Vaz. In: CARDOSO D. (Org.), Pensadores do século XX. São Paulo: Paulus: Loyola, 2012, p. 222-223.
} 
Desse modo, a rememoração é o "tornar presente na atualidade do filosofar de uma longa sequência de problemas, de temas e de sistemas que não foram mais do que a inscrição, no espaço do conceito, das vicissitudes culturais de um tempo" ou, em outras palavras, "a leitura conceptual do presente histórico a partir de toda a substância inteligível do passado"4. Segundo Lima Vaz, portanto, o estudo dos pensadores, de seus textos e de suas ideias, não é um fim em si mesmo. É um meio para que as questões atuais sejam mais bem refletidas. Tal é a tradução vaziana da afirmação de Hegel: "cada um é filho de seu tempo; do mesmo modo, a filosofia é o seu tempo apreendido pelo pensamento"

Em sua longa trajetória de intelectual cristão, Lima Vaz desenvolveu uma reflexão contextualizada no âmbito da modernidade e de sua crise, com os impasses e as angústias que as caracterizam. Diante da absolutização do sujeito e de sua razão, característica do pensamento moderno, mas também da desmitificação desses elementos, que marca seu declínio, ainda seria possível falar em sentido? Que sentido se prospecta para o homem contemporâneo?

Tais considerações ajudam a emoldurar os primeiros passos desta pesquisa. Como seu marco inicial, até mesmo preliminar, deseja-se rememorar aquilo que se poderia chamar de projeto moderno de cultura e civilização, aí incluído o pensamento filosófico. Este é, como se mencionou, o solo em que se desenvolveu o pensamento vaziano, bem como seu privilegiado interlocutor.

\section{Caracterização da modernidade}

\section{Afirma Lima Vaz que}

o termo "modernidade", usado hoje a cada momento e a todo propósito, acaba tendo muito dessas moedas gastas, cuja inscrição tornou-se indecifrável; ou então circula como um mot de passe, cuja significação todos julgam possuir, mas que ninguém consegue explicar qual seja exatamente ${ }^{7}$.

Para não se cair nessa imprecisão apontada por Lima Vaz, deseja-se primeiramente investigar qual a significação histórico-etimológica da palavra modernidade. Sabe-se que ela deriva do advérbio latino modo, que significa

\footnotetext{
${ }^{4}$ EF III, p. 286-287.

${ }^{5}$ HEGEL, G. W. F. Linhas fundamentais da Filosofia do Direito. Campinas: IFCH/UNICAMP, 1998, Prefácio.

6 "A invenção do sentido é, pois, a tarefa humana por excelência e só ao homem, portador do logos, aberto ao ser e à verdade, é dado o supremo risco de enunciar o sentido e de traduzir, assim, as razões do ser em razões do viver". SNS, p. 9.

${ }^{7}$ AM, p. 241.
} 
recentemente, indicando algo próximo na sucessão temporal ou, para usar a linguagem coloquial, algo que está "na moda", em voga. Modernidade seria, pois, sinônimo de tempo presente, atual.

A primeira menção, de que se tem notícia, ao adjetivo modernus é do século VI d. C., sendo uma das últimas heranças do Latim tardio. A partir da era carolíngia, os eruditos europeus começavam a se dar conta de que estavam vivendo em uma época socioculturalmente distinta daquela passada, a que denominaram antiqua, tendo a si mesmos por modernos. O substantivo latino modernitas, contudo, só veio a aparecer no século XII, sendo popularizado nas línguas vernáculas, salvo raras exceções, apenas no século XIX ${ }^{8}$.

A referida distinção ganhou corpo com o desenvolvimento dos estudos lógicos, filosóficos e teológicos - sobretudo com a redescoberta de Aristóteles no século XIII - de modo que a partir do final do século XIV tornou-se comum falar em via antiqua e via moderna, respectivamente o modo de pensar dos seguidores dos mestres do século XIII (como Tomás de Aquino) e o dos seguidores dos "novos" mestres, em geral nominalistas (Guilherme de Ockham, em destaque).

Por essa mesma época, no campo da arte, foi chamado de moderno o estilo gótico, que começava a se impor na arquitetura; na música, surgiu a ars nova, com Philippe de Vitry; na pintura, Giotto inaugurou novo estilo de linguagem figurativa.

Por volta do século XV, difundiu-se na espiritualidade cristã a devotio moderna, que retomou elementos dos Santos Padres, incentivando uma piedade bastante subjetiva, ascética e mística, pautada mais por atitudes interiores que por práticas externas. Sua maior expressão é o célebre opúsculo Imitatio Christi, atribuído a Tomás de Kempis.

Leve-se em consideração que, durante a Idade Média, o adjetivo moderno trazia consigo uma latente ambiguidade, podendo ser tido como um elogio (indicando abertura de mente, atualização, sintonia com a própria época) ou uma crítica (no sentido de mediocridade, superficialidade, gosto pela mudança, ausência de fundamento sólido) ${ }^{9}$.

Finalmente, com os humanistas italianos e, mais tarde, com os iluministas, a designação de moderno ganhou caráter de valoração extremamente positiva: moderna era aquela época em que rebrilhou a luz da razão - que havia refulgido por primeiro na antiguidade greco-romana - afugentando as trevas da tradição, representadas por um medium aevum, um tempo

\footnotetext{
${ }^{8}$ Para os dados históricos, cf. LE GOFF, J. História e memória. Campinas: Ed. Unicamp, 1990, p. 174-179.

${ }^{9}$ Cf. LALANDE, A. Vocabulaire technique et critique de la Philosophie. 10‥ ed. Paris: PUF, 1968, p. 640.
} 
"intermediário" e sem sentido próprio, entre duas grandes eras. Com isso, aparece também a conotação de modernidade como indicativa de um período determinado da história humana. O primeiro a propor tal compreensão foi Petrarca, já em 1341. Nos séculos sucessivos, firmou-se a periodização tripartida da história em antiguidade, medievo e modernidade, à qual se juntou posteriormente a era contemporânea. Os marcos miliares que designam cada fase desse percurso, contudo, são tidos apenas como convenções ou recursos didáticos, sem alcançar consenso absoluto entre os estudiosos ${ }^{10}$.

Os eventos que se podem ver como indicadores da nova época são o Renascimento cultural, primeiramente na Itália e, mais tarde, em vários outros países; a Reforma Protestante, inicialmente em terras germânicas; as grandes navegações e os descobrimentos marítimos, destacando-se nesses feitos os países ibéricos; a Revolução Científica, com Copérnico, Galileu, Kepler e Newton. Trata-se de um momento em que o homem se viu como centro não mais do cosmos físico-astronômico, mas daquele dos significados, dos símbolos, da cultura. Em outras palavras, o descentramento físico do homem moderno corresponde a seu recentramento cultural ${ }^{11}$.

Um pensador fundamental para se entender a modernidade é, sem dúvida, René Descartes (1596-1650), considerado propriamente o pater modernitatis. Descartes dedicou-se a um projeto intelectual bastante personalizado, com o intuito de encontrar bases sólidas para o edifício do saber humano.

O cogito cartesiano é o marco zero da modernidade filosófica, pois estabelece como princípio e fundamento o sujeito pensante. Não mais os elementos primordiais, nem o ser, nem mesmo Deus, mas o indivíduo capaz de autoconsciência e autodecisão seria doravante a pedra angular do pensamento e da realidade, a medida de todas as coisas, já que tudo seria tratado a partir da referência a ele ${ }^{12}$.

\footnotetext{
${ }^{10}$ Didática e convencionalmente, a transição entre a Antiguidade e a Idade Média é dada pela queda do Império Romano ocidental em 476; entre o Medievo e a Idade Moderna, o marco é a queda do Império Romano do Oriente, sediado em Constantinopla, em 1453; o início da Idade Contemporânea é marcado pela Revolução Francesa, em 1789. Para breve síntese das posições de historiadores a respeito de tal periodização, especificamente no que se refere à modernidade, cf. KOBYLINSKI, A. Modernità e postmodernità. Roma: PUG, 1998, p. 19-22. ${ }^{11}$ Cf. RMF, p. 156.

${ }^{12} \mathrm{O}$ cogito, para Descartes, seria a nova base de todo o conhecimento humano: a evidência do ser mediante a evidência do pensar. Ele o formulou por três vezes: no Discurso do método, nas Meditações sobre Filosofia Primeira e nos Princípios de Filosofia. Veja-se em seguida como ele o faz no Discurso: “(...) concluí que, enquanto eu queria pensar que tudo era falso, cumpria necessariamente que eu, que pensava, fosse alguma coisa. E, notando que esta verdade "penso, logo existo" [cogito ergo sum] era tão firme e segura que as mais extravagantes suposições dos céticos não seriam capazes de a abalar, julguei que podia aceitá-la, sem escrúpulo, como o primeiro princípio da Filosofia que procurava". DESCARTES, R. Discurso do método. Brasília: Ed. UnB, 1989, Parte IV, p. 56. Cf. Idem, Meditações sobre Filosofia Primeira. Campinas: Ed. Unicamp, 2004, II, p. 44-45; Idem, Princípios da Filosofia. Lisboa: Presença, 1995, Parte I, §7, p. 55.
} 
A marca indelével deixada por Descartes na história do pensamento - sua herança à modernidade nascente - se encontra, pois, no cogito que, de certo modo, retoma a simetria eleática entre ser e pensar, encontrando, por sua vez, no sujeito humano seu ponto focal, de modo que o paradigma de reflexão passa do ser ao sou, o qual é evidenciado através do penso.

Depois de Descartes, o mundo ocidental não foi mais o mesmo. A efervescência cultural dos inícios da modernidade - em concomitância ou na esteira do pensamento cartesiano, dependendo ou não de sua direta influência - forjou novo modelo de cultura e de civilização propriamente moderno, como vem caracterizado por Hazard:

Uma filosofia que renuncia à metafísica e, voluntariamente, se restringe àquilo que ela pode colher de imediato na alma humana. A ideia de uma natureza (...) que é potente, que é ordenada, que se acorda com a razão: de onde uma religião natural, um direito natural, uma liberdade natural. Uma moral que se fragmenta em muitas morais; o recurso à utilidade social (...). $\mathrm{O}$ direito à felicidade, à felicidade sobre a terra; a luta empreendida contra os inimigos que impedem os homens de serem felizes neste mundo, [como] o absolutismo, a superstição, a guerra. A ciência, que garante o progresso indefinido do homem e, por consequência, sua felicidade. A filosofia, guia da vida. Tais são, ao que parece, as mudanças que foram realizadas sob nossos olhos; tais são as ideias e as vontades que, a partir do final do século XVII, tomaram consciência de si mesmas e se uniram para constituir a doutrina do relativo e do humano ${ }^{13}$.

\section{Interpretação vaziana da modernidade}

Como se poderia aprofundar filosoficamente - o que aqui mais interessa - o conceito de modernidade? Voltando à etimologia, vê-se que modernidade é a condição ou situação em que o elemento central e decisivo é o modo, ou seja, o tempo presente, o atual. Este ganha uma valoração pela qual sobrepuja o passado e se torna o critério de convicções e decisões. Para Lima Vaz, a modernidade é a condição cultural em que o agora é elevado a pedra de toque do pensar e do agir ${ }^{14}$. Nisso se pode notar a distinção entre uma civilização tradicional, em que o antigo tem precedência sobre o novo, e uma civilização moderna, em que ocorre o inverso. Nas palavras de Lima Vaz,

É necessário, pois, que a representação do tempo tenha perdido a estrutura repetitiva própria da simbólica do mito, ou tenha sido transposta da lógica

\footnotetext{
${ }^{13}$ HAZARD, P. La crise de la conscience européenne (1680-1715). Paris: Boivin \& Cie, 1935, p. 346-347.

${ }^{14}$ Segundo Lima Vaz, “(...) o termo modernidade implica etimologicamente uma referência temporal à qual se acrescenta um juízo de valor sobre o tempo propriamente histórico. Com efeito, a modernidade designa um determinado modo de se viver o tempo presente como tempo privilegiado a partir do qual se empreende uma avaliação antecipadora do futuro". HH, p. 158.
} 
do idêntico para a dialética do idêntico e do diferente, para que o agora ou o atual do tempo possa revestir-se de uma novidade qualitativa e o tempo presente assuma uma dignidade, vem a ser, uma estrutura axiológica capaz de desqualificar a primazia do antigo e pôr em questão a instância normativa de um passado fixado na antiguidade de uma origem, diante da qual o presente deva abdicar da sua novidade ${ }^{15}$.

Tal feito, de acordo com a hermenêutica vaziana, aconteceu com a civilização jônia do século VI a. C., cenário do nascimento do pensar filosófico, com a descoberta da razão demonstrativa (logos apodeiktikos). Desse modo, “(...) a filosofia situada no presente da reflexão pode conferir ao mesmo presente a dignidade de instância de compreensão e julgamento do passado, ou a dignidade do novo que advém ao tempo como diferenciação qualitativa na identidade de seu monótono fluir" ${ }^{16}$.

O pensamento filosófico, portanto, é essencialmente moderno e a modernidade é essencialmente filosófica, havendo uma sinonímia entre tais conceitos. A história da filosofia, bem como a história da civilização ocidental que a desenvolveu, pode ser considerada a sucessão de modernidades, que se reconheceram como tais. A diacronia é, pois, uma característica fundamental da modernidade, da filosofia e do ocidente. Neste mesmo viés, numa síntese de elevada precisão, Perine define a modernidade como “(...) categoria de leitura diacrônica do tempo histórico a partir do agora privilegiado do ato de filosofar" ${ }^{17}$.

De que modo tal conceito, abrangente em seu espectro de aplicação, pode ser tomado como indicativo de um período bem demarcável da história humana? O que faz aquela modernidade - cuja manhã radiosa se viu na formulação do cartesianismo - ser propriamente moderna, para se tornar a modernidade por antonomásia?

Sempre seguindo o referencial vaziano, pode-se dizer que tal modernidade moderna $^{18}$ caracteriza-se por formular novas concepções de sujeito e de razão. De fato, os modernos encontraram no sujeito humano, núcleo do pensar e do decidir, a arché procurada desde os primeiros filósofos. Ora, se modernidade é a instauração do agora do filosofar como critério fun-

\footnotetext{
${ }^{15}$ RMF, p. 149.

${ }^{16} \mathrm{RMF}, \mathrm{p} .149$.

17 PERINE, M. A modernidade e sua crise. Síntese, n. 57, 1992, p. 174.

${ }^{18}$ Lima Vaz utiliza a expressão modernidade moderna em seu artigo Religião e modernidade filosófica, que foi revisado e ampliado quando de sua inserção em EF III. Nessa nova versão, o autor deixou de usar a expressão acima, substituindo-a por modernidade pós-cristã. Em suas palavras: “Na versão anterior deste texto, usamos a expressão 'modernidade moderna' para designar as modernidades que se sucedem no Ocidente pós-renascentista. Preferimos aqui substituí-la pela expressão 'modernidade pós-cristã' que designa inegavelmente, em termos de valores fundamentais, uma das características constantes dessas modernidades". EF III, p. 235 , nota 27.
} 
damental para a civilização, pergunta-se: quem é aquele que filosofa, que experimenta o inexorável fluir do tempo, que constrói a sociedade? E o homem. A modernidade moderna nada mais faz, pois, que imanentizar no sujeito humano o fundamento da existência, do pensamento e da ação, em suma, o fundamento do sentido. Primeira e decisiva expressão disso é o cogito, ergo sum de Descartes.

O sujeito apresenta-se, assim, como o hypokeimenon, a substância primeira que sustenta todo o edifício simbólico da cultura moderna (...). A Denkform da modernidade ocidental tem, por conseguinte, no sujeito assim definido, sua evidência primeira e o primeiro princípio de sua ordem de razões ${ }^{19}$.

De acordo com Lima Vaz, pode-se indicar o início da modernidade ainda vigente com a atuação de Descartes ${ }^{20}$, mais especificamente, com a redação de sua primeira obra mais significativa, as Regras para a orientação do espírito, escritas em 1629, mas publicadas apenas após sua morte. Incontestavelmente, como já se acenou, a reflexão cartesiana está na base da modernidade. A ela acrescente-se o aporte de Galileu no campo da ciência e de Hobbes na ética ${ }^{21}$.

Pode-se dizer, pois, que o sujeito moderno apresenta-se como indivíduo que se põe como fundamento do pensar e do agir. Com efeito, a transposição para a imanência do sujeito do até então transcendente princípio decisivo sobre a verdade e a falsidade, o bem e o mal, o ser e o não-ser, assinala em profundidade o pensamento moderno. É uma nova e mais acurada edição da homomensura protagoriana, que no início dos tempos modernos se encontra nas virtualidades do cogito cartesiano, visibiliza-se ainda mais no sujeito transcendental kantiano e ganha plena expressão na nietzscheana vontade de potência, marca distintiva do Übermensch.

Lima Vaz aborda de vários ângulos o tournant imanentista que caracteriza a irrupção da modernidade. Para que se verifique como ele o faz,

\footnotetext{
${ }^{19}$ SNS, p. 11.

20 "A relação da filosofia com o tempo inaugura, a partir de Descartes, um tipo de modernidade até então inédito na nossa 'civilização filosófica', ao operar a imanentização no próprio sujeito do ato de filosofar, do fundamento que confere a esse mesmo ato seu privilégio no tempo". RMF, p. 155. Podem-se ainda conferir os juízos de Hegel e Heidegger sobre o caráter inaugural do cartesianismo: "Com Descartes entramos, em rigor (...), em uma filosofia própria e independente, que sabe que procede substantivamente da razão e que a consciência de si é um momento essencial da verdade (...). Com Descartes começa, com efeito, verdadeiramente, a cultura dos tempos modernos, o pensamento da moderna filosofia". HEGEL, G. W. F. Lecciones sobre la Historia de la Filosofía, III. Ciudad del México: Fondo de Cultura Económica, 1997, p. 252; "Descartes antecipou o fundamento metafísico da modernidade, o que não significa que toda a filosofia subsequente não seria senão cartesianismo (...). O fundamento não podia ser outro a não ser o próprio homem, na medida em que o sentido da nova liberdade lhe impedia toda vinculação e todo elemento imperativo que não emergissem de seus próprios posicionamentos". HEIDEGGER, M. Nietzsche II. Rio de Janeiro: Forense Universitária, 2007, p. 109.
}

${ }^{21}$ Cf. ERM, p. 80, nota 25; p. 71. 
seja permitida uma sequência de algumas citações, ordenadas cronologicamente:

A profunda revolução operada nas estruturas simbólicas do ethos da sociedade ocidental a partir do século XVII tem origem com a imanentização do fundamento transcendente que assegurava a suprassunção dialética da oposição entre a práxis humana e o seu mundo (...). Seja como for, o que emerge desse revolver profundo do solo histórico do Ocidente é a figura paradigmática do homem que levanta a formidável pretensão de ser o fundamento e o lugar conceptual do movimento de transcendência no qual é suprassumida, no nível dos valores, normas e fins universais, a oposição entre a práxis humana e seu mundo enquanto situados na particularidade de seu acontecer empírico. Pretensão formidável, com efeito, essa em que a práxis humana se propõe como capaz de dar a si mesma o seu próprio fundamento, de ser a fonte última de sua própria teoria, de constituir-se, em suma, no sentido mais estrito, como criadora do seu mundo, vem a ser, do universo da cultura e do ethos que lhe é consubstancial. As filosofias do sujeito, expressão simbólica por excelência desse prometeísmo antropológico da modernidade, são a sua consagração filosófica, assim como o individualismo é a sua consagração ideológica ${ }^{22}$.

(...) o advento da modernidade vem assinalar a primeira vez em que o homem levantou a pretensão de absorver na imanência da sua liberdade, as razões e o fundamento do seu ethos ${ }^{23}$.

Se a modernidade, considerada do ponto de vista da filosofia, implica no seu conceito uma avaliação, pelo homem, do seu tempo histórico, avaliação que se traduz no privilégio reconhecido ao modo ou à atualidade do segmento desse tempo no qual se exerce o pensamento próprio da modernidade, então o problema fundamental desse pensamento é o problema do fundamento do privilégio que advém ao tempo pelo exercício, nele, do ato de filosofar (...). Ou esse fundamento é buscado num Princípio transtemporal ou transcendente ao tempo (...). Ou esse fundamento é suposto residir no próprio sujeito do ato de filosofar, em cuja imanência se dará a suprassunção do tempo empírico na atualidade de um saber que finalmente irá proclamar-se absoluto. Esse o fundamento metafísico da "modernidade moderna", colocada sob a égide da razão cartesiana ${ }^{24}$.

(...) o ciclo da modernidade pode ser considerado como aquele no qual o homem ocidental refaz a morada simbólica de sua existência no mundo (...). Ora, entregar-se à tarefa dessa reconstrução implica, em última instância, avocar a si o intento propriamente demiúrgico de edificar um mundo submetido a um sistema de medidas imanente ao próprio homem, ou ainda ensaiar, como projeto de civilização, a transposição (...) do paradigma do homem-medida, proposto por Protágoras em plena crise da modernidade grega $^{25}$.

${ }^{22}$ ECI, p. 12

${ }^{23}$ ECO, p. 8.

${ }^{24}$ RMF, p. $158-159$.

${ }^{25}$ SNS, p. 6. 
(...) um dos aspectos mais frequentemente analisados na fenomenologia da modernidade diz respeito à iniciativa teórica, até agora inédita na história humana, que propugna a imanentização dos termos da relação de transcendência, com a abolição da sua dimensão metafísica e a emergência do existente humano como fonte do movimento de autotranscendência desdobrando-se na esfera da imanência: nas instituições do universo político, na construção do mundo técnico, na concepção autonômica do agir ético, na fundamentação teórica, enfim, da visão do mundo ${ }^{26}$.

Chama-se a atenção para a insistência com que o filósofo jesuíta trata desta questão, em vários escritos pertencentes a momentos distintos de sua produção filosófica, como se pôde ver acima. Essas citações fazem perceber o modo como Lima Vaz entende a gênese do sujeito moderno em sua autoproclamação como fundamento de si e do mundo, em sua reivindicação de não ser tutelado por nenhuma outra instância (religiosa, acadêmica, sociopolítica) senão por si mesmo. Para ele, o "prometeísmo antropológico da modernidade" - fenômeno que se constitui como seu interlocutor privilegiado - manifesta-se no sujeito que descobre em si a fonte, o critério e a medida de suas ações e de seu pensamento; entende-se como construtor do mundo, da sociedade, da cultura e de sua própria existência; vê-se como doador de sentido a tudo; acaba por reduzir seu congênito movimento de autotranscendência ao horizonte intra-histórico e, portanto, imanente ${ }^{27}$. A busca da mais elevada autonomia emerge, assim, como o DNA do homem moderno. Nessa perspectiva, como não se recordar do modo pelo qual o filósofo de Königsberg definia o Iluminismo (Aufklärung)?

Aufklärung é a saída do homem de sua menoridade, da qual ele próprio é culpado. A menoridade é a incapacidade de fazer uso de seu entendimento sem a direção de outro indivíduo. O homem é o próprio culpado dessa menoridade se a causa dela não se encontra na falta de entendimento, mas na falta de decisão e coragem de servir-se de si mesmo sem a direção de outrem. Sapere aude! Tem coragem de fazer uso de teu próprio entendimento! - tal é o lema da Aufklärung 28 .

Tal sujeito reveste-se da forma histórica do indivíduo. Este seria o resíduo da lenta dissolução das pequenas comunidades, como a família, os grupos culturais e religiosos, em que as pessoas buscavam alento na satisfação de suas necessidades simbólicas e encontravam referências para sua vida ética $^{29}$. Não se pode deixar de mencionar que a formação do conceito de

\footnotetext{
${ }^{26}$ EF VII, p. 16.

${ }^{27}$ Poder-se-ia concluir que a modernidade é, por si mesma, ateia ou, na melhor das hipóteses, agnóstica, tese que, em certa medida, de fato, se verifica. Contudo, a questão de haver ou não um lugar para Deus tem sido uma constante no pensamento moderno.

${ }^{28}$ KANT, I. Resposta à pergunta: Que é Aufklärung?. In: Idem, Textos seletos. 4ª ed. Petrópolis: Vozes, 2008, p. 63-64 [com pequena adaptação].

${ }^{29}$ Cf. EF III, p. 139-151. Em outra perspectiva, M. Horkheimer oferece uma sugestiva análise da noção de indivíduo: cf. HORKHEIMER, M. Ascensão e declínio do indivíduo. In: Idem, Eclipse da razão. Rio de Janeiro: Labor do Brasil, 1976, p. 139-172.
} 
indivíduo na modernidade está certamente ligada ao abandono da analogia, substituída pela univocidade, como categoria que permite entender a dinâmica da constituição dos entes e da atividade racional, bem como de sua inter-relação ${ }^{30}$. Assim, pode-se afirmar que o indivíduo moderno é univocamente monádico em sua essência, postulando uma autonomia absoluta $^{31}$. Paradoxalmente, o indivíduo moderno é também social, já que não pode escapar à grande sociedade política, sendo forçado muitas vezes a abdicar de suas pretensões em nome do "contrato social", entendido seja ao modo hobbesiano, seja ao rousseauniano. Para Lima Vaz, o indivíduo “(...) é permanentemente intimado a tornar-se outro a partir de sua própria identidade penosamente conquistada, a arrancar-se de si mesmo, a alienar-se, em suma, a tornar-se social" ${ }^{\prime 32}$.

Por outro lado, que ideia de razão se depreende do posicionamento cartesiano e da nova impostação do sujeito? Qual sua originalidade em relação à razão clássica?

A razão clássica, entendida como logos apodeiktikos (discurso demonstrativo), foi desenvolvida a partir dos antigos pensadores gregos como abertura intencional ao todo do ser, cuja operação seria a de expressá-lo de modo ordenado e reflexivo. Nas palavras de Lima Vaz, pode-se definir a razão, assim considerada, “(...) pela sua abertura transcendental ao Ser, ou seja, pela sua identidade dialética com o Ser, e pela sua total reflexividade em si mesma; identidade e reflexividade que, na nossa razão finita, tem lugar no domínio do intencional"33. Tal faculdade era vista em sua unidade

\footnotetext{
${ }^{30}$ A analogia, como uma característica fundamental do ente e da atividade do logos, está presente no pensamento clássico, recebendo de Tomás de Aquino seus mais intensos tons. No ocaso da Idade Média, a partir de Duns Scotus, a primazia é dada à univocidade, em detrimento da analogia, o que irá se confirmar ao longo da modernidade, alterando o rumo do pensar filosófico. Este é um tema bastante estudado ultimamente. Cf. COURTINE, J.-F. Inventio analogiae: Métaphysique et ontothéologie. Paris: Vrin, 2005.

${ }^{31}$ A implícita referência a Leibniz não é acidental. Com efeito, em sua teoria das mônadas, Leibniz consagra o caráter absoluto do indivíduo acima de todo universal, levando às últimas consequências o nominalismo medieval. "O indivíduo não é uma evanescente manifestação do universal, mas aquilo que existe de mais real no universo. E o mundo é maravilhoso não porque é uma única substância, mas porque é um conjunto harmonioso de infinitos indivíduos ou mônadas, cada uma das quais reflete em si todos os outros indivíduos ou mônadas (...). Estamos de fato nas antípodas dos sistemas monísticos. Aqui está a consagração de um pluralismo oceânico (...). O universo é como uma orquestra enorme em que cada músico executa perfeitamente a sua parte, em sintonia com todos os outros". MONDIN, B. Storia della Metafisica, v. III. Bologna: Studio Domenicano, 1998, p. 213. Certamente, Leibniz não pensava direta e principalmente nos indivíduos humanos nem mesmo nas características que o predomínio do individualismo nas sociedades modernas poderia comportar, mas no conjunto das substâncias singulares que compõem o cosmos. Contudo, foi naquele sentido que se desenvolveu posteriormente o predomínio dado ao indivíduo. Uma análise muito instigante da emergência do indivíduo moderno a partir desta perspectiva é oferecida em RENAUT, A. A era do indivíduo. Lisboa: Instituo Piaget, 2000.

${ }^{32}$ EF VII, p. 15-16.

${ }^{33}$ ERM, p. 60.
} 
analógica ${ }^{34}$, pela qual a razão humana finita poder-se-ia entender em referência à suprema razão divina que lhe ofereceria, ao mesmo tempo, suporte, modelo e completude ${ }^{35}$.

De acordo com Aristóteles, a razão se autodiferenciaria em três âmbitos distintos e complementares, a que corresponderiam três dimensões do saber humano: poiético, prático e teórico ${ }^{36}$. O saber poiético é aquele produtivo, voltado à fabricação de coisas úteis à vida humana, encontrando sua finalidade e realização em algo exterior ao homem. O saber prático é aquele que diz respeito à práxis, ao agir humano enquanto humano, preocupando-se não com o resultado concreto da ação, mas com esta propriamente. Assim, seu télos está no sujeito que pratica a ação, enquanto se aperfeiçoa no e através do agir. O saber teórico é aquele que vale por si mesmo, apontando para algo além da poiésis e da práxis, algo que dá sentido a ambas e que é encontrado pela contemplação que busca o fundamento último do ser e do agir $^{37}$. Segundo o Estagirita, seria a filosofia, em sua componente metafísica, o saber teórico por excelência que presidiria os outros âmbitos do conhecimento como verdadeira sabedoria ordenadora. Tal concepção, mutatis mutandis, permaneceu durante o Medievo, conservando à filosofia o papel de saber ordenador, ainda que a teologia fosse considerada a ciência mais elevada ${ }^{38}$.

A razão moderna rompe com tal harmonia na ordem do saber devido à acentuação do poiético sobre o prático e o teórico. Com efeito, posicionando o sujeito como seu centro e fundamento, ela se manifesta como uma razão essencialmente operacional e calculadora, já que o interesse pela theoría em seu sentido mais próprio se perde, por se considerar inacessível seu objeto (o que Kant designa de númeno ou coisa em si) e a

\footnotetext{
${ }^{34}$ A estrutura da razão, em chave analógica, postula uma bipolaridade harmoniosa entre seu aspecto metafísico (ser) e seu aspecto lógico (representação). Aquele permite pensar a infinitude real do ser; este trabalha com a infinitude intencional da própria razão. Se no período clássico (antigo-medieval) predominou o primeiro polo, na modernidade predomina o segundo. Cf. ERM, p. 64-65; SNS, p. 6-7.

35 “Como identidade absoluta com o Ser, a Razão é noûs ou intellectus. Na nossa razão finita, a identidade com o Ser é uma identidade na diferença: a identidade intencional (cognoscitiva) com o Ser admite a diferença real com o Ser subsistente em si mesmo, independentemente de nosso conhecimento. Nossa razão está, pois, estruturalmente articulada à identidade intencional com a universalidade do Ser ou, em outras palavras, é estruturalmente ordenada ao seu ato supremo como inteligência" ERM, p. 64. A tal tema Lima Vaz dedicou profundas e inspiradas páginas ao abordar a categoria de espírito (razão e liberdade) em sua Antropologia Filosófica. Cf. AF I, p. 208-213; 218-237.

${ }^{36}$ Cf. ARISTÓTELES. Metafísica [São Paulo: Loyola, 2002], VI, 1, 1025b 21-25; Idem, Ética a Nicômaco [São Paulo: Abril Cultural, 1984], VI, 3, 1139b 14-36.

37 "Assim, a theoría é o termo de uma linha sem ruptura traçada pelo percurso do logos que ultrapassa o domínio da práxis ou do ocupar-se com as coisas humanas (...) para penetrar na esfera do divino, objeto da contemplação que é, ela mesma, algo de sobre-humano e divino". EF II, p. 129, nota 218.

${ }^{38}$ Cf. ERM, p. 61.
} 
práxis se rege pelo critério da utilidade. A razão moderna não mais será contempladora do cosmos ou de Deus ou das essências, mas voltada para o próprio sujeito humano e fabricadora daquilo que ele pode conceber e realizar por si mesmo, ou seja, uma razão demiúrgica. A teoria, retirada de seu locus originário, entrelaça-se com o poiético num híbrido know-how que descarta a priori a mediação do prático (ético) e se impõe como saber dominante ${ }^{39}$. Ocorre, assim, o surgimento da ciência empírico-formal, de caráter físico-matemático, pela qual o sujeito constrói um mundo a partir de si mesmo, um mundo de objetos técnicos ou $\operatorname{artificiais~}^{40}$. O papel determinante ocupado pela tecnociência nas últimas décadas é a face mais evidente da primazia do poiético. De acordo com Lima Vaz, tal feito se tornou possível devido ao predomínio do polo lógico da razão e não mais do polo metafísico:

Na razão moderna, o polo lógico assumirá, portanto, a primazia no universo da razão e essa primazia é ratificada em Descartes pelo predomínio do método e em Kant pela emergência do sujeito transcendental que, como operador do método e construtor do objeto, acabará avocando para si o lugar e a dignidade do Absoluto real. Se na razão clássica as formas de racionalidade ordenam-se à inteligência metafísica, no domínio da razão moderna as formas de racionalidade multiplicam-se e se ordenam a partir dos procedimentos metódicos fundamentais da experimentação e da construção lógica do objeto (...). Conhecimento como cálculo e conhecimento como poder, tais as marcas distintivas das racionalidades modernas, que tornam realidade em todo o âmbito da nossa cultura o sonho cartesiano de um mundo matematizado ${ }^{41}$.

Assim se passa do paradigma do ser ao da representação, ou seja, do ontológico ao lógico ${ }^{42}$ o que caracteriza a emergência da modernidade, já

${ }^{39}$ Cf. ERM, p. 61.

${ }^{40}$ Lima Vaz se refere a esse fenômeno também em termos de primazia da categoria antropológica da objetividade. Esta é uma dentre as estruturas fundamentais do ser humano e diz respeito à sua relação com o mundo (cf. AF II, p. 9-48). Na modernidade, a categoria de objetividade ganha relevância sobre as demais (intersubjetividade e transcendência), na medida em que o mundo é objeto privilegiado da explicação científica e da transformação técnica, por meio das quais deixa de ser um cosmos dado (ou physis) para se tornar um mundo construído pelo gênio produtivo do homem moderno. Tudo o mais que compõe a vida humana passa também a ser regido pelos critérios da categoria de objetividade, como a funcionalidade, a produtividade e a utilidade. Aí estaria o predomínio do poiético.

${ }^{41}$ ERM, p. 65.

${ }_{42}$ "Na sua acepção gnosiológica, ou seja, tal como aqui a entendemos, a teoria da representação é uma teoria do conhecimento intelectual que confere novo estatuto gnosiológico à necessária representação do objeto na imanência do sujeito cognoscente. A representação deixa de ser apenas o sinal formal que reenvia imediatamente ao objeto na sua realidade extramental, para constituir-se em termo imediato, em id quod da intenção cognoscitiva. Essa teoria deve enfrentar, de um lado, a solução do difícil problema da relação entre o cognoscente e a coisa conhecida pela mediação da representação. De outro, ela tende a erigir, nas suas versões idealistas, a representação como norma e medida imanente da cognoscibilidade do objeto". SNS, p. 7. 
que a representação mental se torna a medida imanente do conhecer, do pensar e do decidir ${ }^{43}$.

Tal fato se mostra, de um lado, com o declínio da metafísica em seu sentido clássico (theoría) e, de outro, com o avanço da gnosiologia entendida como filosofia primeira, de Descartes a Husserl ${ }^{44}$, bem como da tecnociência, ao modo positivista, como um saber para poder ${ }^{45}$.

$\mathrm{Na}$ modernidade, várias formas ou figuras de racionalidade se fazem presentes, todas sob o paradigma mencionado acima. Lima Vaz enumera entre as figuras de racionalidades: a lógico-matemática, principal matriz da razão moderna; a empírico-formal, própria das ciências naturais, cujo modelo é a Física; a hermenêutica, própria das ciências humanas, que abordam o universo cultural; a filosófica, fundada na logicização do $\operatorname{ser}^{46}$. No dizer de Lima Vaz,

O traço comum dessas racionalidades é o seu caráter operacional, que impele um permanente processo de modificação do mundo da vida e retira progressivamente toda legitimidade objetiva às outras vias de acesso à realidade como a tradição, a crença, o senso comum, confinados à esfera das necessidades subjetivas do indivíduo ${ }^{47}$.

Qual seria o lugar da filosofia diante das ciências que se desenvolvem na modernidade? Seria a filosofia também uma ciência entre as outras? Lima Vaz constata que, em algumas concepções, a filosofia é tida como uma meta-ciência, uma ciência das ciências, estudando a validade de seus métodos (procedimentos) e resultados (técnica). Em outras vertentes, ela

\footnotetext{
${ }^{43} \mathrm{Tal}$ passagem do ser à representação, profundamente relacionada àquela da analogia à univocidade, dá o tom do pensamento moderno. Cf. BOULNOIS, O. Etre et représentation. Paris: PUF, 2008.

${ }^{44}$ Malgrado a generalidade da afirmação, pode-se dizer com acerto que a metafísica moderna, elaborada por Descartes e Leibniz, sistematizada por Wolff e criticada energicamente por Kant, ganhará cada vez mais nítidos aspectos de teoria do conhecimento. Mesmo Kant a considerará como metafísica da natureza (do dado), ao lado de sua pretendida metafísica dos costumes (da liberdade). Husserl, quem sabe o último grande moderno, continuará nessa linha, tendo como base do pensar filosófico uma teoria fenomenológica do conhecimento centrada no sujeito, que ele entendia como "filosofia primeira". Cf. EF III, p. 343-367. Ver ainda HUSSERL, E. Filosofia prima. Soveria Mannelli: Rubbettino, 2007.

${ }^{45}$ Em alguns textos, Lima Vaz usa a expressão "absolutização da práxis", entendendo-se aqui práxis não mais no sentido aristotélico, mas como junção do agir (esfera do ethos) e do produzir (esfera da poiésis), contrapondo-se ao contemplar (esfera da theoría). Cf. EF II, p. 208-224 e EF III, p.115-118. Desse modo, pode-se dizer que, na modernidade, tem-se simultaneamente a fusão sui generis do teórico com o poiético, produzindo um saber técnico-científico dos meios e não dos fins, bem como a fusão do prático com o poiético, dando origem a uma ditadura da práxis autônoma (em que o poiético goza de função normativa), cujo raio de alcance atinge todas as esferas da vida individual e social, com a primazia do útil. Cf. SNS, p. 12.

${ }^{46}$ Cf. ERM, p. 66-69. "Se essa intencionalidade não aponta mais para o polo metafísico, ela deve necessariamente retornar sobre si mesma e orientar-se para o polo lógico enquanto imanente ao próprio sujeito, seja como princípio da ordem racional do seu discurso, seja como fundamento da sua aprioridade transcendental sobre o dado da experiência". ERM, p. 73.

${ }^{47}$ EF VII, p. 101, nota 6.
} 
se mostra como uma racionalidade alternativa àquela, nas formas de pensamento fenomenológico, existencial ou hermenêutico. De qualquer modo, renunciando ao modelo da metafísica clássica, a filosofia moderna tende a fechar-se numa imanência inapelável, cedendo espaço às ideologias e à irrupção de formas do irracional como tentativas de oposição ao domínio da tecnociência ${ }^{48}$.

Não se entenda, porém, que Lima Vaz se coloque em contraposição aos legítimos avanços e conquistas da modernidade. Com a possibilidade de um conhecimento mais aprofundado da natureza e sua utilização em benefício do ser humano em vários setores - como, por exemplo, a medicina; sem se esquecer da revalorização do homem em sua dignidade pessoal e social, no campo dos direitos humanos e na constituição de Estados democráticos - a modernidade oferece ganhos à humanidade ${ }^{49}$.

O ponto problemático em questão está no postulado da racionalidade técnica de se arvorar em única racionalidade possível, rechaçando qualquer abertura ao que Aristóteles chamou de saberes teóricos e práticos. O homem, demiurgo do novo mundo forjado pela técnica, acaba por se tornar objeto e, por vezes, marionete de sua própria invenção ${ }^{50}$. Questões como a do sentido da vida não encontram mais lugar neste contexto; o plano imanente ou horizontal da existência se torna absoluto, com uma recusa a qualquer transcendência vertical ${ }^{51}$. Como consequência, "a racionalidade

${ }^{48}$ Cf. ERM, p. 69.

49 "Supérfluo dizer que não se trata aqui de propormos uma avaliação negativa nem das grandes e benéficas transformações na infraestrutura material da sociedade, tornadas possíveis pelo aperfeiçoamento constante do instrumental científico-técnico, nem de tantas e fecundas ideias nos campos filosófico, científico, jurídico, político, pedagógico que nasceram e cresceram no clima da modernidade". HH, p. 164. Veja-se ainda: EF II, p. 181-224; 263-279; EF VII, p. 282; RIBEIRO, E. V. Reconhecimento ético e virtudes. São Paulo: Loyola, 2012, p. 91-101. 50 "A tecnociência é, indiscutivelmente, a mais poderosa força cultural que arranca o homem do contorno fechado da repetição e do instinto onde o prendem as necessidades 'naturais' e o atira no espaço sem fronteiras de um logos que se dilata ao infinito. Aí, no entanto, um novo e muito mais grave risco de perda no mundo dos objetos o ameaça - dos objetos sem vida e sem alma do sistema técnico - se ele não restabelecer as referências da sua interioridade propriamente humana, ou seja, as dimensões de um ethos no interior do qual possa habitar como homem". EF II, p. 224. Veja-se também: OLIVEIRA, M. A. A filosofia na crise da modernidade. São Paulo: Loyola, 1990, p. 73-83. Ainda que em perspectiva distinta da que faz Lima Vaz, Heidegger refletiu de modo crítico a respeito da técnica como instância absoluta da vida humana na era contemporânea. Cf. HEIDEGGER, M. A questão da técnica. In: Idem, Ensaios e conferências. Petrópolis: Vozes, 2001, p. 11-38.

${ }^{51}$ Cf. EF VII, p. 190. Corroborando tal afirmação, ainda que a partir de outro viés, escreve Umberto Galimberti: “O paradigma técnico-científico, de fato, não se propõe alguma finalidade a realizar, mas somente resultados a alcançar, como êxitos de seus procedimentos. Esta abolição dos fins destitui, desde os fundamentos, toda possível busca de sentido (...). A este tipo de pergunta a técnica não responde, porque a categoria do sentido não pertence às suas competências. Mas, como hoje a técnica tornou-se a forma do mundo, o último horizonte além de todos os horizontes, as questões acerca do sentido vagam ansiosas e sem resposta numa terra já abandonada pelo seu céu (...)". GALIMBERTI, U. L'ospite inquietante: Il nichilismo e i giovani. Milano: Feltrinelli, 2009, p. 18. 
técnico-científica acaba por colocar em segundo plano o bem mais precioso da modernidade: a subjetividade" ${ }^{52}$.

A razão, considerada pelos modernos como paradigma absoluto de civilização, parece ter-se fragilizado em seus usos e nas consequências destes à medida que tal civilização foi-se historicamente concretizando, assim como um rei acaba por perder o controle de seu reino sob o influxo de interesses e desarticulações das peças-chave do governo, ainda que aparecendo aos olhos dos súditos como gloriosamente reinante. Tais considerações já introduzem a questão acerca da crise da modernidade, assunto do próximo ponto.

\section{Uma crise enigmática}

Crise é um conceito não raro no repertório filosófico do século $\mathrm{XX}$, nele comparecendo de modo direto e indireto. Referindo-se especificamente à crise da modernidade, assevera Manfredo Oliveira que "uma crise é, em primeiro lugar, uma crise de sentido e, consequentemente, do valor de todas as coisas. É todo o sentido do mundo do passado, sobretudo em sua forma moderna, que está sendo posto em questão" ${ }^{\prime 53}$.

Diante de tal horizonte de crise, muito se tem escrito ultimamente a respeito da plausibilidade de se estar em uma era pós-moderna ou, ao contrário, em um momento distinto da mesma modernidade "moderna" 54 .

O pensamento pós-moderno, como movimento filosófico, pode ter seu início assinalado com a publicação da obra $A$ condição pós-moderna, de J.-F. Lyotard $^{55}$. Neste escrito, que seu próprio autor reconhece como ocasional ${ }^{56}$,

\footnotetext{
52 OLIVEIRA, C. M. R. Metafísica e ética: A filosofia da pessoa de Lima Vaz como resposta ao niilismo contemporâneo. São Paulo: Loyola, 2013, p. 48.

${ }^{53}$ OLIVEIRA, M. A. A filosofia na crise da modernidade. São Paulo: Loyola, 1990, p. 7. Paul Hazard postula que a civilização europeia conheceu uma crise deste tipo nos inícios da modernidade, em que se passou de um período proto-moderno (que se poderia classificar como sendo de matiz renascentista) para uma fase de maturidade da cosmovisão moderna, entre os anos de 1680 e 1715. Para uma ideia geral desta leitura hermenêutica, veja-se a introdução de tal obra: HAZARD, P. La crise de la conscience européenne (1680-1715). Paris: Boivin \& Cie, 1935, p. V-X.

${ }^{54}$ Tal assunto não se poderá examinar aqui em maior detalhe. Para fundamentação e aprofundamento, cf. KOBYLINSKI, A. Modernità e postmodernità. Roma: PUG, 1998, p. 43-54.

${ }^{55}$ Em geral, os filósofos ditos pós-modernos são praticamente identificados com os também chamados de pós-estruturalistas, como o já mencionado J.-F. Lyotard, mas também M. Foucault, G. Deleuze, J. Derrida e J. Baudrillard. A eles podem-se acrescentar R. Rorty e G. Vattimo. Tais autores que, diga-se de passagem, em geral não aceita(ra)m a designação de pós-modernos, estão entre os mais estudados atualmente. Para uma primeira visão, ainda que parcial, deste panorama, cf. CONNOR, S. Pós-modernidades. In: Idem, Cultura pós-moderna: Introdução às teorias do contemporâneo. São Paulo: Loyola, 2000, p. 29-56.

${ }^{56}$ LYOTARD, J.-F. La condition postmoderne. Paris: Minuit, 1979, p. 9.
} 
mas que vem produzindo grande impacto na cultura contemporânea, Lyotard aponta para o fim das grandes narrativas e dos sistemas de ideias (como o iluminismo, o idealismo, o marxismo) que legitimavam o saber na modernidade, bem como para o declínio do saber metafísico.

Segundo Lyotard, a ciência moderna, cujas afirmações advêm de constatações empíricas de dados de fato, teria desbancado os antigos métodos de legitimação do saber organizados em chave narrativa ou, vale dizer, simplesmente teórica. Paradoxalmente, a própria ciência estaria baseada, por sua vez, em (meta)narrativas, como as de cunho positivista (o mito do progresso e a lei comtiana dos três estágios), mas não só estas. Cada escola filosófica moderna (e também os sistemas éticos, políticos, religiosos etc) teria forjado seus modos específicos de fundamentar o saber e o proceder, todos, é claro, demonstrando sua confiança na capacidade da razão. Justamente isto é que vem posto em xeque pelo pensamento pós-moderno. A desconfiança na possibilidade humana de descobrir verdades certas e seguras, "claras e distintas", a respeito do mundo e de si mesmo torna-se, paradoxalmente, o dogma fundamental do pós-modernismo. Afirmações científicas e filosóficas seriam apenas pontos de vista razoavelmente fundamentados, mas sempre cambiáveis e flutuantes ${ }^{57}$.

Pouco mais de trinta anos depois da publicação do citado livro de Lyotard, entretanto, o que permanece da proposta pós-moderna? Ao que parece, tem-se um cenário paradoxal. De um lado, a koiné pós-moderna ganhou muito espaço nos ambientes acadêmicos de ensino e pesquisa, basta ver a grande quantidade de dissertações e teses defendidas recentemente, em âmbito nacional e internacional, que abordam o pensamento de Foucault, Deleuze e Vattimo, bem como suas raízes nietzscheanas e/ou heideggerianas, ou ainda a variante sociológica de análise do fenômeno pós-moderno presente, por exemplo, na obra de Z. Bauman. De outra parte, o âmbito do mundo vivido mostra-se dotado de permeabilidade seletiva para com os ideais pós-modernos: questões tidas como de foro interno (existenciais, morais, religiosas) são facilmente modeláveis por eles, o que faz alastrar o relativismo e o niilismo; mas o modus operandi das instâncias de foro externo (sócio-político-econômicas) permanece essencialmente moderno, com as características de sistematicidade, planejamento, cálculo, competitividade, globalização. Ademais, a ciência continua em seu vertiginoso itinerário de pesquisas, descobertas e inovação tecnológica, sem se importar com metanarrativas, presentes ou não, que fundamentem sua atividade, mas levando sempre em consideração o impacto mercadológico de seus "produtos" 58 .

${ }^{57}$ Cf. Ibidem, p. 29-35; 54-68.

${ }^{58}$ Afirma, a propósito, Pondé: “Mesmo que muitos intelectuais 'brinquem' de pós-modernos, afirmando que tudo é 'simulacros ou narrativas', aviões voam e transplantes de órgãos acontecem seguindo as 'convenções' da física e da biologia. Mesmo que descubramos que as mesas são constituídas de 'espaços vazios', continuaremos a colocar pratos em cima delas sem que caiam no 'vazio quântico'”. PONDÉ, L. F. Do pensamento no deserto: Ensaios de Filosofia, Teologia e Literatura. São Paulo: EDUSP, 2009, p. 241. 
O que se pode perceber é que, no contexto filosófico contemporâneo, há certo pudor, para não dizer descrença, sarcasmo e/ou temor, em relação àquilo que a tradição denominou os transcendentais: o ser, a verdade, a bondade, a beleza. Busca-se uma ciência sem a verdade, uma ética sem o bem, uma estética sem a beleza, uma filosofia sem o ser e, até mesmo, uma espiritualidade sem Deus. Chegando-se aos extremos desta posição, não existiria de fato nem o que se chama de real, mas apenas interpretações ${ }^{59}$. Em outras palavras, mantêm-se as aparências, mas sob elas jaz somente o vazio. (Continua)

Endereço Autor:

R. Profa. Lourdes de Faria, 99

São Carlos

37557-013 Pouso Alegre - MG

pejuliano@yahoo.com.br

\footnotetext{
${ }^{59}$ Veja-se, a propósito, VATTIMO, G. Oltre l'interpretazione: Il significato dell'ermeneutica per la filosofia. Bari: Laterza, 1994, p. 3-19. Incisiva é também a afirmação de Foucault: "A todos aqueles que desejam ainda falar do homem, do seu reino e da sua libertação, a todos aqueles que propõem ainda perguntas sobre o que é o homem em sua essência, a todos aqueles que desejam partir dele para ter acesso à verdade (...), a todas essas formas de reflexão desajeitadas e falsificadas, não se pode senão contrapor um riso filosófico - isto é, em parte silencioso". FOUCAULT, M. Les mots et les choses: Une archéologie des sciences humaines. Paris: Gallimard, 1966, p. 353-354.
} 